\title{
Estimasi Persentase Karbon Organik Di Hutan Mangrove Bekas Tambak, Perancak, Jembrana, Bali
}

\author{
I Gusti Agung Indah Mahasani ${ }^{\mathrm{a} *}$, Nuryani Widagti ${ }^{\mathrm{b}}$, I Wayan Gede Astawa Karang ${ }^{\text {a }}$ \\ ${ }^{a}$ Faculty of Marine Science and Fisheries, Udayana University, Bukit Jimbaran, Bali 80361, Indonesia \\ ${ }^{b}$ Balai Penelitian dan Observasi Laut, Kementerian Kelautan dan Perikanan, Perancak, Jembrana, Bali 82251, Indonesia \\ * Penulis koresponden. Tel.: +62-361-702-802 \\ Alamat e-mail: indahmahasani@gmail.com
}

\begin{abstract}
Mangrove forests in the coastal regions are very effective and efficient in reducing the concentration carbon dioxide (CO2) in the atmosphere, because mangroves can absorb CO2 through photosynthesis by diffusion through the stomata and then store carbon in the form of biomass. The purpose of this study, namely: (1) Determine the percentage of organic carbon in the soil in former mangrove forest ponds in Perancak and (2) Determine the vertical variation of the percentage of organic carbon stored in soils in former mangrove forest ponds in Perancak. The method used from this study is the loss on ignition (LOI). The average percentage of organic carbon in mangrove forest area of the former farm of $50.181 \% \mathrm{C}$ or $184.618 \mathrm{Mg} / \mathrm{ha}$. The average vertical variations of each depth, that is: depth $(0-15 \mathrm{~cm}) 50.487 \%$ C, $(15-30 \mathrm{~cm}) 50.781 \% \mathrm{C}$, $(30-50 \mathrm{~cm}) 50.550 \%$ C, $(50-100 \mathrm{~cm}) 51.689 \% \mathrm{C}$, and (> $100 \mathrm{~cm}) 47.396$ $\%$ C.
\end{abstract}

Keywords: former mangrove forest ponds; organic carbon stored

\section{Pendahuluan}

Hutan mangrove merupakan ekosistem peralihan antara daratan dan lautan yang terjadi di sebagian besar sepanjang garis pantai tropis dan subtropis (Liu et al., 2014). Hutan mangrove di wilayah pesisir sangat efektif dan efisien dalam mengurangi konsentrasi karbondiokisda (CO2) di atmosfer, dikarenakan mangrove dapat menyerap $\mathrm{CO} 2$ melalui proses fotosintesis dengan cara difusi lewat stomata kemudian menyimpan karbon dalam bentuk biomassa. Menurut Sugirhayu (2011) simpanan karbon pada hutan alam, hutan rawa, dan agroforestri tidak jauh berbeda, yaitu masing-masing sebesar 37,2846 ton/ha; 39,2875 ton/ha; dan 36,8416 ton/ha, sedangkan mangrove memiliki simpanan karbon terbesar, yaitu sebesar 51,5031 ton/ha.

Tidak hanya itu hutan mangrove menyediakan jasa ekosistem yang penting, dan memainkan peran penting dalam terestrial dan siklus karbon kelautan (C). Meskipun stok $\mathrm{C}$ atau penyimpanan dalam ekosistem darat telah sering dinilai, stok $\mathrm{C}$ di hutan mangrove sering diabaikan (Liu et al., 2014). Hutan mangrove adalah hutan yang paling dominan penyimpanan karbon dari hutan laninya, dengan sebagian besar dialokasikan secara proporsional lebih banyak karbon di bawah tanah (Alongi, 2012).

Kawasan mangrove yang beada di daerah Perancak, Jembrana-Bali, merupakan kawasan mangrove yang ditanam di bekas lahan tambak dan ada juga di tanah alami. Dari hasil penelitian (Lunstrum, 2014) menyatakan bahwa konsentrasi C-organik pada tanah untuk kedalaman tanah 1 meter $0.62 \%$ - $2.43 \%$ pada hutan mangrove alami. Dan dari hasil penelitian (Anugriati et al., 2013) dengan metode yang berbeda diperoleh kandungan Corganik tanah di tambak Kabupaten Demak bervariasi dari
0,51 sampai 2,72 \% dengan rata-rata 1,60 \%. Karakteristik tanah secara alami dapat berbeda-beda secara terusmenerus dalam waktu dan tempat yang berbeda. Oleh karena itu, perlu dilakukannya penelitian mengenai stok karbon di bawah permukaan tanah secara keseluruhan di hutan mangrove Perancak, Jemberana, Bali.

\subsection{Tujuan}

Tujuan penelitian ini adalah:

1. Mengetahui persentase karbon organik pada tanah di hutan mangrove bekas tambak di Perancak.

2. Mengetahui variasi secara vertikal persentase karbon organik yang tersimpan dalam tanah di hutan mangrove bekas tambak di Perancak.

\subsection{Manfaat}

Manfaat yang diharapkan dari penelitian ini adalah:

1. Dapat digunakan sebagai informasi tentang potensi karbon organik yang terkandung dalam tanah di hutan mangrove bekas tambak di Perancak.

2. Dapat digunakan sebagai gambaran apakah terdapat variasi secara vertikal pada karbon organik yang terkandung dalam tanah yang ada di hutan mangrove bekas tambak di Perancak.

\section{Metode dan Bahan}

\subsection{Waktu dan Lokasi Penelitian}

Sampel sedimen untuk analisis persentase karbon organik diambil di 3 (tiga) lokasi, yaitu P1 (Pond 1) dengan koordinat S: 8²3’29.2” dan E: 144³7’39.1”, P2 (Pond 2) dengan koordinat S: 8²3’38.4” dan E: 144³7.'52.6”, dan 
P3 (Pond 3) dengan koordinat S: $8^{\circ} 23^{\prime} 39.6^{\prime}$ dan E: 144³7'42.4”. Lokasi tersebut dulunya merupakan hutan mangrove yang kemudian dialihfungsikan menjadi tambak, dan ditanami kembali dengan mangrove hingga tumbuh seperti saat ini (restored-mangrove). Lokasi pengambilan sampel dapat dilihat pada Gambar 2.1.

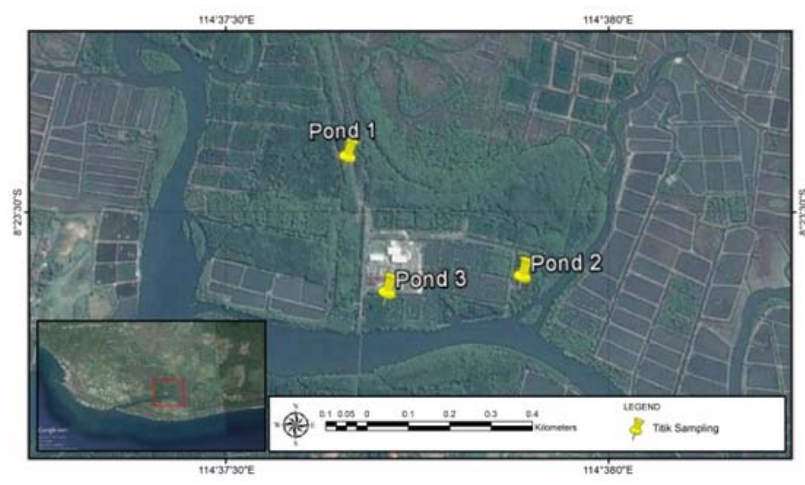

Gambar 1. Peta Lokasi Penelitian

\subsection{Alat dan Bahan}

Alat dan bahan yang digunakan untuk mengukur estimasi persentase karbon organik di hutan mangrove bekas tambak di Perancak ditampilkan pada Tabel 1.

\subsection{Prosedur Pengambilan Sampel}

Data yang diperlukan untuk menghitung persentase karbon organik dalam tanah adalah kedalaman sampel tanah, kedalaman dan interval sub-sampel, dan bulk density (kerapatan massa jenis). Untuk mengetahui hal tersebut, tahapan kerja yang perlu dilakukan, sebagai berikut:

1. Sebelum dilakukan pengambilan sampel dengan menggunakan opened-face Auger, bersihkan sampah organik dan daun hidup (jika ada) dari permukaan tanah;

2. Lakukan coring dengan memasukan perangkat openedfaced Auger ke dalam tanah secara vertikal di lokasi yang sudah ditentukan sampai kedalaman mencapai pangkal corer. Jika coring tidak dapat menembus kedalaman penuh (sampai pangkal corer), maka carilah lokasi lain untuk pengambilan sampel. Ketika corer telah mencapai kedalaman penuh, putar corer untuk memotong akar halus yang terdapat dalam tanah. Kemudian tarik perlahan corer dari dalam tanah sambil terus diputar, untuk mempertahankan agar sampel sedimen yang diambil tetap penuh dan lengkap;

\section{Tabel 1}

Frekuensi Relatif, Kerapatan Relatif, Dominansi Relatif dan Nilai Indek Penting Jenis Tumbuhan Mangrove Tingkat Pohon.

\begin{tabular}{ll}
\hline \multicolumn{1}{c}{ Alat } & \multicolumn{1}{c}{ Kegunaan } \\
\hline Meteran (Measuring & $\begin{array}{l}\text { Untuk mengukur panjang } \\
\text { (kedalaman) sampel sedimen dan } \\
\text { memudahkan dalam menentukan } \\
\text { sub-sampel yang akan diambil }\end{array}$ \\
Pisau tipis dan tajam & $\begin{array}{l}\text { Untuk mengiris (slicing) sampel } \\
\text { dan sub-sampel }\end{array}$
\end{tabular}

\begin{tabular}{|c|c|}
\hline Alat & Kegunaan \\
\hline Sendok kecil & $\begin{array}{l}\text { Untuk memudahkan dalam } \\
\text { pengambilan sampel dan juga } \\
\text { dalam memasukannya ke dalam } \\
\text { plastik sampel }\end{array}$ \\
\hline $\begin{array}{l}\text { Open-faced Auger } \\
\text { (sediment corer) }\end{array}$ & $\begin{array}{l}\text { Untuk mengambil sampel } \\
\text { sedimen, dapat juga digunakan } \\
\text { untuk menentukan kedalaman } \\
\text { tanah }\end{array}$ \\
\hline Oven (Memmert) & $\begin{array}{l}\text { Untuk mengeringkan sampel } \\
\text { sedimen, sebelum dibakar dalam } \\
\text { muffle furnace }\end{array}$ \\
\hline $\begin{array}{l}\text { Timbangan Analitik } \\
\text { (Ohaus) }\end{array}$ & $\begin{array}{l}\text { Untuk menimbang sampel } \\
\text { sedimen }\end{array}$ \\
\hline $\begin{array}{l}\text { GPSmap 76CS } x \\
\text { (Garmin) }\end{array}$ & $\begin{array}{l}\text { Untuk mengambil koordinat lokasi } \\
\text { pengambilan sampel }\end{array}$ \\
\hline $\begin{array}{l}\text { Kantong plastik } \\
\text { (zipper-bag) }\end{array}$ & $\begin{array}{l}\text { Untuk menyimpan sempel, } \\
\text { sebelum dianalisis di laboratorium }\end{array}$ \\
\hline $\begin{array}{l}\text { Cawan sampel } \\
\text { (Aluminium) }\end{array}$ & $\begin{array}{l}\text { Untuk menempatkan sampel } \\
\text { selama pengeringan di dalam oven } \\
\left(60^{\circ} \mathrm{C}\right)\end{array}$ \\
\hline Mortar & $\begin{array}{l}\text { Untuk menghaluskan sampel } \\
\text { (samples homogenizing) }\end{array}$ \\
\hline Crucible porcelain & $\begin{array}{l}\text { Untuk menempatkan sampel } \\
\text { selama pembakaran sampel dalam } \\
\text { muffle furnace }\left(450^{\circ} \mathrm{C}\right)\end{array}$ \\
\hline Kertas label & $\begin{array}{l}\text { Untuk memberikan tanda atau } \\
\text { keterangan sampel yang diambil }\end{array}$ \\
\hline Alat tulis & $\begin{array}{l}\text { Untuk mencatat hal-hal penting } \\
\text { terkait dengan pengambilan } \\
\text { sampel di lapangan, seperti waktu, } \\
\text { kondisi habitat (jenis dominan), } \\
\text { cuaca, volume Auger (r1 dan r2), } \\
\text { dan lain-lain. }\end{array}$ \\
\hline Kamera & $\begin{array}{l}\text { Untuk arsip dokumentasi sampel } \\
\text { (nomor sampel, kedalaman, dan } \\
\text { lain-lain) dan kegiatan selama di } \\
\text { lapangan dan di laboratorium } \\
\text { (proses kerja dan kondisi } \\
\text { lingkungan) }\end{array}$ \\
\hline
\end{tabular}

3. Setelah diperoleh sampel sedimen yang lengkap dan utuh, sampel tersebut kemudian dibelah (secara horizontal), dan dibagi berdasarkan 5 kedalaman (5 sampel), yaitu $0-15 \mathrm{~cm}, 15-30 \mathrm{~cm}, 30-50 \mathrm{~cm}, 50-100$ $\mathrm{cm}$, dan $>100 \mathrm{~cm}$. Tidak seluruh sampel sedimen diambil, tetapi dengan menentukan sub-sampel dari masing-masing sampel tersebut. Sampel pada kedalaman 0-15 cm hanya diambil pada kedalaman 5$10 \mathrm{~cm}$, kedalaman 15-30 cm hanya sampel pada kedalaman 20-25 cm, kedalaman 30-50 cm hanya sampel pada kedalaman 35-40 cm, kedalaman 50-100 cm hanya sampel pada kedalaman 70-80 cm, dan pada kedalaman $>100 \mathrm{~cm}$ hanya sampel pada kedalaman 105-110 cm yang diambil;

4. Masukan sub-sampel ke dalam zipper bag dan berikan label pada setiap kantong untuk memudahkan identifikasi dan analisis di laboratorium; dan

5. Masukan sampel kedalam cool box (jika lokasi pengambilan data jauh dari laboratorium tempat analisis sampel) atau tempat khusus untuk dibawa ke laboratorium. 


\subsection{Prosedur Analisis Sampel di Laboratorium}

Setelah pengambilan sampel di lapangan selesai, kemudian sampel dianalisis di laboratorium dengan metode loss on ignition (LOI). Tahapan analisis tersebut adalah (Howard, J et al., 2014):

1. Sampel sedimen ditempatkan dalam cawan alumunium, kemudian dimasukan ke dalam oven yang sudah diatur suhu $\left(60^{\circ} \mathrm{C}\right)$ dan waktunya (48 jam);

2. Setelah kering, sampel kemudian digerus atau dihaluskan dengan menggunakan mortar agar kondisi setiap sub-sampel menjadi homogen sebelum dilakukan pembakaran. Tempatkan setiap sub-sampel yang sudah dihaluskan tersebut kedalam kantong plastik (zipper bag); dan

3. Timbang sebanyak \pm 2 gram sampel yang sudah dihaluskan, kemudian tempatkan pada crucible porcelain. Masukan sampel tersebut ke dalam muffle furnace dan bakar dengan suhu $450^{\circ} \mathrm{C}$ selama 4 jam, kemudian timbang kembali.

\subsection{Alat dan Bahan}

Data yang akan dihitung adalah kedalaman sampel sedimen, bulk density, dan persentase karbon organik pada sedimen. Adapun perhitungan yang di gunakan dalam menganalisis data sebagai berikut (Howard, J et al., 2014):

1. Bulk density tanah merupakan berat partikel persatuan volume tanah beserta porinya. Rumus yang digunakan untuk menghitung bulk density (BD) disajikan pada persamaan 1:

$$
\text { Soll bulk density }\left(\mathrm{g} \mathrm{cm}^{-8}\right)=\frac{\text { Oven-dry mass }(\mathrm{g})}{\text { Sample Volume }\left(\mathrm{om}^{3}\right)}
$$

2. Densitas Karbon (C) dihitung dengan menggunakan persamaan 2:

Soil C density (g C cm-3) = \% C X BD (Soil bulk density)

3. Kandungan karbon pada tanah diestimasi dengan persamaan 3:

Soil C (Mg ha-1) = BD X SDI (Soil Depth Interval) X \% C (3)

\section{Hasil dan Pembahasan}

Dari hasil penelitian di tiga pond hutan mangrove bekas tambak Perancak didapatkan hasil yang berbeda, dimana jenis pohon yang terdapat pada setiap pond berbeda, pada pond pertama jenis pohon mangrove yang mendominasi adalah jenis Rhizopora stylosa, pada pond ini kawasan hutan mangrove dekat dengan jalan raya, pada pond dua hutan mangrove dekat dengan sungai, pohon mangrove yang mendominasi adalah jensis Ceriaps tagal dan Bruguera jgymnorhiza dan pada pond ketiga hutan mangrove dekat dengan muara sungai jenis pohon yang mendominasi adalah jenis Rhizopora apiculata. Pada penelitian ini sampel sedimen diambil dalam 5 lapisan berbeda secara vertikal, yaitu pada kedalaman 0-15 cm, 15-30 cm, 30-50 cm, 50-100 cm, dan >100 cm. Pengambilan sampel pada ke tiga pond berbeda, dimana pada pond 1 dan kedua sampel di ambil pada sore hari, sedangkan pada pond ketiga seampel diambil pada pagi hari.

\subsection{Bulk Density}

Bulk Density menunjukkan bobot massa tanah pada kondisi lapangan yang telah dikering-ovenkan per satuan volume. Dari hasil analisis, diketahui bahwa tanah pada masing-masing pond dan pada masing-masing kedalaman memiliki nilai bulk density berbeda. Semakin tinggi nilai bulk density kepadatan tanah semakin tinggi. Dari ketiga pond yang berbeda nilai bulk density tertinggi berada pada bagian bawah. Nilai bulk density pada kawasan hutan mangrove masih tergolong rendah dibandngkan dengan perkebunan kelapa sawit sebesar 1,413 g/ $\mathrm{cm}^{3}$ (Sugirhayu 2011). Dimana penyusun partikel tanah mangrove didominasi oleh pasir. Dengan banyaknya pori-pori makro maka tanah dengan dominasi pasir akan memiliki kemampuan menahan air yang sangat rendah, sehingga kerapatan tanahnya rendah. Selain itu, tanah tersebut akan mudah mengalami pencucian. Bulk density di lapisaan permukaan lebih rendah di bandingkan laisan bawah. Menurut Eid and Shaltout (2015) menyatakan bahwa semanakin menikngkatnya kedalaman hutan mangrove di Laut Merah Mesir nilai bulk density juga meningkat.

Dapat dilihat pada Gambar 2, nilai bulk density pada masing-masing pond berbeda-beda secara vertikal. Nilai tertinggi bulk density pada pond I dan III terdapat pada bagian bawah di kedalaman $>100 \mathrm{~cm}$ dengan nilai sebesar $0.113 \mathrm{~g} / \mathrm{cm}^{3}$ dan $0.202 \mathrm{~g} / \mathrm{cm}^{3}$. Sedangkan pada pond 2 nilai tertinggi bulk density berada pada kedalaman 15-30 $\mathrm{cm}$ dengan nilai sebesar $0.144 \mathrm{~g} / \mathrm{cm}^{3}$. Nilai bulk density terendah pada masing-masing pond berbeda-beda tidak seperti nilai tertinggi rata-rata terdapat pada bagian bawah.

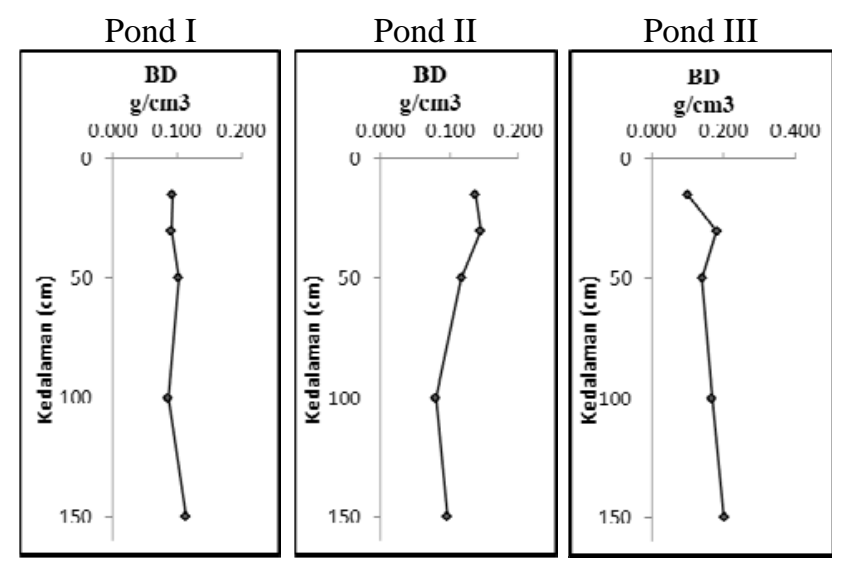

Gambar 2. Grafik perbandingan bulk density

Pada Gambar 3 dapat dilihat nilai rata-rata bulk density tertinggi terdapat pada dua kedalaman yang berbeda yaitu kedalaman 15-30 cm dan >100 cm denagn nilai sebesar $0.139 \mathrm{~g} / \mathrm{cm}^{3}$ dan $0.137 \mathrm{~g} / \mathrm{cm}^{3}$. Sedangkan nilai terendah terdapat pada kedalaman yaitu $0-15 \mathrm{~cm}$ dan 50-100 cm, dengan niali sebesar $0.110 \mathrm{~g} / \mathrm{cm}^{3}$ dan 0.112 $\mathrm{g} / \mathrm{cm}^{3}$. 


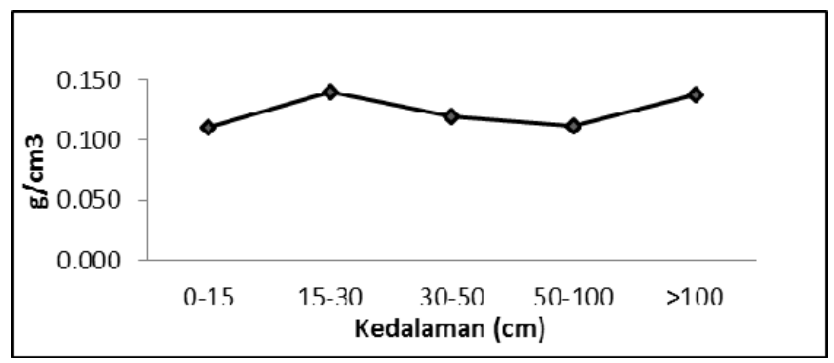

Gambar 3. Grafik rata-rata bulk density

\subsection{Simpanan Karbon}

Hasil pengukuran persentase karbon pada tiga pond memiliki hasil simpanan karbon yang berbeda. Nilai simpanan karbon diukur secara vertikal dengan kelima kedalaman yang berbeda adapun kedalaman yang di ukur yaitu 0-15 cm, $15-30 \mathrm{~cm}, 30-50 \mathrm{~cm}, 50-100 \mathrm{~cm}$, dan $>100$ $\mathrm{cm}$. Dimana masing-masing kedalaman memiliki nilai simpanan karbon berbeda. Simpanan karbon tertinggi pada ketiga pond sama, berada pada kedalaman 50-100 $\mathrm{cm}$, dengan nilai masing-masing pond sebesar $51.57 \%$, $51.23 \%$ dan 52.26 \%. Dan nilai terendah pada ketiga pond terdapat pada bagian bawah dengan nilai masingmasing sebesar $45.63 \%$, $47.31 \%$ dan $49.23 \%$. Nilai yag berbeda di pengaruhi oleh jumlah dan kerapatan pohon, jenis pohon, faktor lingkungan yang meliputi penyinaran matahari, kadar air, suhu, dan kesuburan tanah yang mempengaruhi laju fotosintesis. Dimana saat pengambilan data kondisi pada sata tersebut berbeda-beda, pada pond I dan pond II diambil pada hari yang sama disore hari, sedangkan pada pond III diambil pada pagi hari. Total simpanan karbon pada pond pertama sebesar 142,310 Mg ha $^{-1}$. Pada pond kedua total simpanan karbon sebesar 165,027 $\mathrm{Mg} \mathrm{ha}^{-1}$, sedangkan total simpanan pada pond ketiga sebesar 246,517 $\mathrm{Mg} \mathrm{ha}^{-1}$.
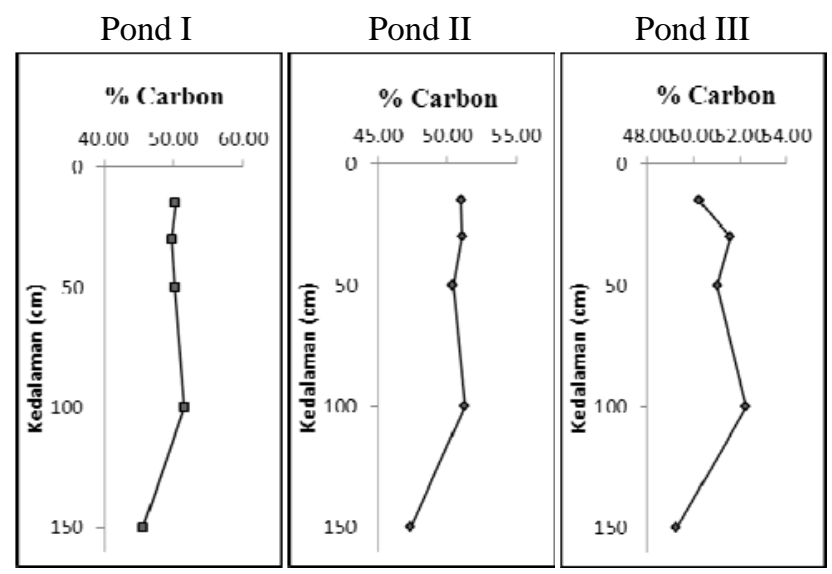

Gambar 4. Grafik perbandingan persentase karbon organic

Pada Gambar 5 terlihat nilai rata-rata simpanan karbon pada ketiga pond. Dari hasil rata-rata ketiga pond tersebut diperoleh nilai persentase karbon tertinggi pada kedalaman 50-100 cm sebesar $51.69 \%$, sedangkan niali terendah terdapat pada lapisan paling bawah dengan kedalaman $>100 \mathrm{~cm}$ sebesar $47.40 \%$. Rata-rata persentase karbon organik pada daerah hutan mangrove bekas tambak sebesar 50,181 \%C atau 184,618 Mg ha- ${ }^{-1}$. Simpanan karbon pada hutan mangrove meiliki simpanan terbesar dari hutan-hutan lainnya. Hutan mangrove memilik simpanan karbon terbesar, yaitu sebesar 51.5031 ton/ha (Sugirahayu, 2011). Dengan metode alometrik kandungan karbon sedimen di Kepulauan Derawan sebesar 23,26 dan 27,92 Mg hä (Afiati dkk., 2014).

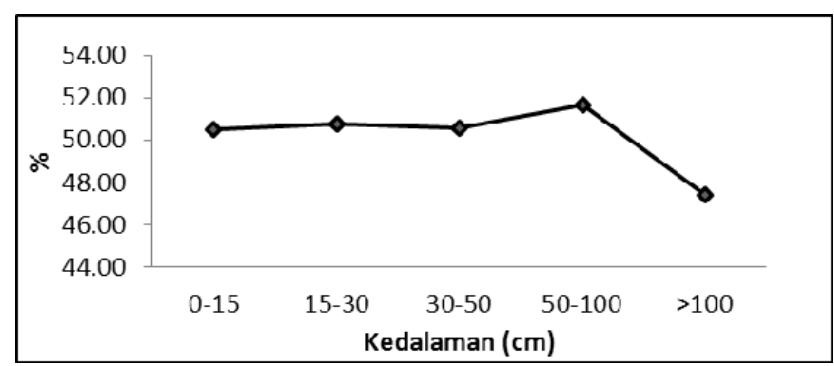

Gambar 5. Grafik rata - rata persentase karbon organik

\subsection{Kepadatan Karbon Tanah $\left(\mathrm{g} \mathrm{cm}^{-3}\right)$}

Pada setiap pond dengan kedalaman yang berbeda memiliki nilai karbon yang berbeda (Gambar 3.5). Pada setiap pond dilakukan pengambilan sampel secara vertikal kedalam lapisan tanah dengan lima lapisan yang berbeda, yaitu 0-15 cm, 15-30 cm, 30-50 cm, 50-100 cm, dan >100 cm. Pada masing - masing pond di setiap kedalaman nilai yang didapat berbeda. Pada pond I nilai yang di peroleh pada kelima lapisan yang berbeda, yaitu untuk kedalaman 0-15 cm sebesar 0.046 g cm-3, kedalaman 15-30 cm sebesar 0.045 g cm-3, kedalaman 30-50 cm 0.051 g cm-3, kedalaman 50-100 cm sebesar 0.045 g cm-3 , dan kedalaman $>100 \mathrm{~cm}$ sebesar $0.051 \mathrm{~g} \mathrm{~cm}-3$. Pada pond II nilai yang di peroleh perlapisan kedalaman, yaitu pada kedalaman 0-15 cm sebesar $0.070 \mathrm{~g} \mathrm{~cm}-3$, kedalaman 15$30 \mathrm{~cm}$ sebesar $0.074 \mathrm{~g} \mathrm{~cm}-3$, kedalaman $30-50 \mathrm{~cm} 0.059 \mathrm{~g}$ cm-3, kedalaman 50-100 cm sebesar $0.040 \mathrm{~g} \mathrm{~cm}-3$, dan kedalaman $>100 \mathrm{~cm}$ sebesar $0.045 \mathrm{~g} \mathrm{~cm}-3$. Dan pada pond III nilai pada masing - masing kedalaman, yaitu pada kedalaman 0-15 cm sebesar $0.051 \mathrm{~g} \mathrm{~cm}-3$, kedalaman 15$30 \mathrm{~cm}$ sebesar $0.094 \mathrm{~g} \mathrm{~cm}-3$, kedalaman $30-50 \mathrm{~cm} 0.072 \mathrm{~g}$ cm-3, kedalaman 50-100 cm sebesar $0.088 \mathrm{~g} \mathrm{~cm}-3$, dan kedalaman $>100 \mathrm{~cm}$ sebesar $0.099 \mathrm{~g} \mathrm{~cm}-3$. Nilai tertinggi terdapat pada pond 3 di kedalaman $>100 \mathrm{~cm}$ dengan nilai sebesar $0.099 \mathrm{~g} \mathrm{~cm}-3$, sedangkan nilai terendah terdapat pada pond 2 di kedalaman 50-100 cm dengan nilai sebesar $0.040 \mathrm{~g} \mathrm{~cm}-3$.

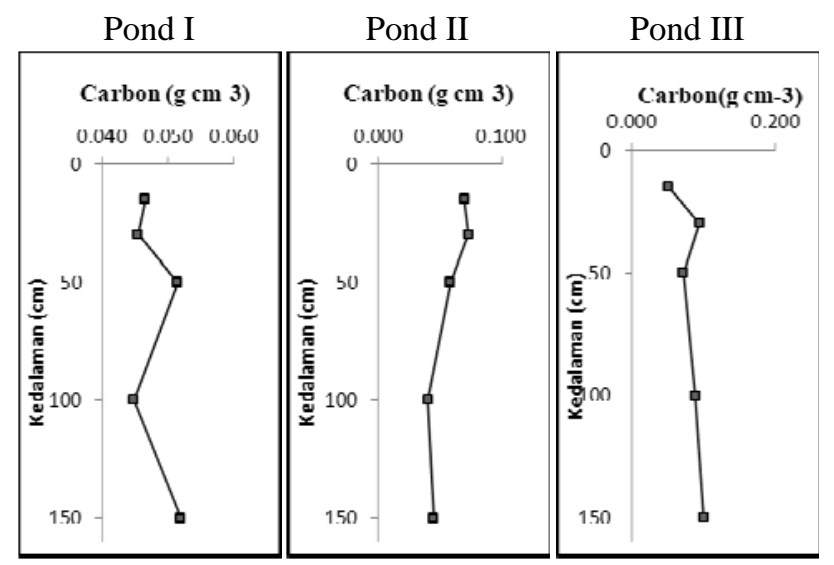

Gambar 6. Grafik perbandingan kepadatan karbon tanah $\left(\mathrm{g} \mathrm{cm}^{-3}\right)$ 
Dari hasil analisis didapat nilai kepadatan karbon tanah rata - rata dari setiap pond dan diperoleh nilai yang berbeda - beda (Gambar 3.6). Dari hasil rata - rata ketiga pond tersebut diperoleh nilai kepadatan karbon tanah tertinggi pada kedalaman $15-30 \mathrm{~cm}$ dengan nilai sebesar $0.071 \mathrm{~g} \mathrm{~cm}-3$, sedangkan niali terendah terdapat pada bagian permukaan dengan kedalaman 0-15 cm sebesar $0.056 \mathrm{~g} \mathrm{~cm}-3$.

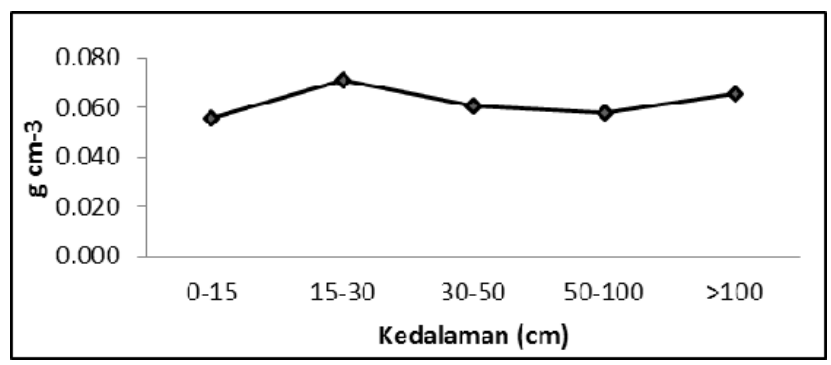

Gambar 7. Grafik rata - rata kepadatan karbon tanah $\left(\mathrm{g} \mathrm{cm}^{-3}\right)$

\section{Simpulan dan Saran}

\subsection{Simpulan}

Dari hasil pembahasan di atas, maka dapat ditarik suatu kesimpulan yaitu, rata - rata persentase karbon organik pada daerah hutan mangrove bekas tambak sebesar 50,181 \%C atau 184,618 Mg/ha. Dan rata - rata persen karbon organik secara vertikal pada daerah mangrove bekas tambak berfluktuasi, pada lapisan permukaan $(0-15 \mathrm{~cm})$ nilai karbon organik sebesar 50,487 \%C, pada lapisan kedua (15- $30 \mathrm{~cm}$ ) nilai karbon organik sebesar 50.781 $\%$, pada lapisan ketiga $(30-50 \mathrm{~cm})$ nilai karbon organik sebesar $50.550 \%$, pada lapisan keempat $(50-100 \mathrm{~cm})$ nilai karbon organik sebesar 51.689 \%C, dan pada lapisan terakhir $(>100 \mathrm{~cm})$ nilai karbon organik sebesar 47.396 $\%$ C.

\subsection{Saran}

Berdasarkan hasil yang diperoleh selama penelitian ada beberapa saran yang diajukan yaitu, sebaiknya pengukuran estimasi persentase karbon organik pada tanah dilakukan secara berkelanjutan untuk mengetahui bagaimana perubahan penyimpanan karbon secara temporal.

\section{Ucapan terimakasih}

Penulis mengucapkan banyak terima kasih kepada Bapak I Wayan Gede Astawa Karang, S.Si, M.Si, Ph.D. selaku dosen pembimbing dan Nuryani Widagti, M.Si. selaku dosen pembimbing lapangan yang selalu memberikan saran dan masukan dalam pembuatan jurnal ilmiah ini. Penulis juga mengucapkan banyak terima kasih kepada Balai Penelitian dan Observasi Laut (BPOL) yang telah bersedia membantu dalam penelitian ini.

\section{Daftar Pustaka}

Afiati dkk., 2014. Karbon Stok dan Stuktur Komunitas Sebagai Blue Carbon di Kepulauan Derawan, Kalimantan Timur. Prosiding Seminar Hasil Penelitian Terbaik Tahun 2014. Badan Penelitian dan Pengembangan Kelautan dan Perikanan.

Alongi, D.M., 2012. Carbon Sequestration in Mangrove Forests. Carbon Manage. 3, 313-322.

Anugriati, et al., 2013. Distribusi Spasial Karakteristik Kimia Tanah Tambak di Kabupaten Demak, Provinsi Jawa Tengah. Fakultas Ilmu Perikanan, Universitas Hasanuddin. Makassar.

Eid, E. M. and Shaltout, K. M. 2015. Distribution of Soil Organic Carbon in the mangrove Avicennia marina (Forssk.) Vierh. Along the Egyptian Red Sea Coast. Regional Studies in Marine Science.

Howard, J., Hoyt, S., Isensee, K., Telszewski, M., Pidgeon, E. 2014. Coastal Blue Carbon: Methods for Assessing Carbon Srocks and Emission Factors in Mangroves, Tidal Salt Marshes, and Seagrass Meadows. Conservation Internasional, Intergovernmental Oceanographic Commission of UNESCO, Internasional Union for Conservastion of Nature. Virginia, USA.

Liu, H., et al., 2014. Carbon Stocks and Potential Carbon Storage in the Mangrove Forests of China. Jurnal of Envirinmental Management 133. 86-93.

Lunstrum, A. dan Chen, L. Soil Carbon Stocks and Accumulation in Young Mangrove Forests. Journal Soil Biology \& Biochemistry 75. 223-232.

Sugirahayu, L. 2011. Perbandingan Simpanan Karbon Pada Beberapa Penutupan Lahan Di Kabupaten Paser, Kalimantan Timur Berdasarkan Sifat Fisik dan Sifat Kimia Tanahnya. [Skripsi]. Departemen Silvikultur, Fakultas Kehutanan, Institut Pertanian Bogor.

(C) 2015 by the authors; licensee Udayana University, Indonesia. This article is an open access article distributed under the terms and conditions of the Creative Commons Attribution license (http://creativecommons.org/licenses/by/3.0/). 